\title{
Illness Expectations Assessment in People with Asthma: A Tool for Explicit and Implicit Beliefs
}

\author{
Francesco Pagnini $\mathbb{D}^{1,2}$ \\ Eleonora Volpato $\mathbb{1}^{1,3}$ \\ Silvia Dell'Orto' \\ Cesare Cavalera (D) \\ MariaFrancesca Spina ${ }^{3}$ \\ Paolo Banfi $\mathbb{1}^{3}$ \\ 'Department of Psychology, Università \\ Cattolica del Sacro Cuore, Milan, Italy; \\ ${ }^{2}$ Department of Psychology, Harvard \\ University, Cambridge, MA, USA; \\ ${ }^{3}$ Pneumological Rehabilitation, IRCCS \\ Fondazione Don Carlo Gnocchi, Milan, \\ Italy
}

Correspondence: Francesco Pagnini Department of Psychology, Università Cattolica del Sacro Cuore, Via Nirone,

I5, CAP, Milan, 20I23, Italy

Tel +393391942425

Email francesco.pagnini@unicatt.it
Background: Illness expectations are cognitive schemas, both explicit and implicit, describing how symptoms are expected to be in the future. They can be particularly relevant to disease in a mind/body framework. Asthma is a condition in which the psychological aspects can highly influence the body, but no study has directly explored these specific expectations, and no dedicated assessment tools are available.

Methods: We developed a questionnaire to assess the illness expectations, together with an ad hoc version of the Implicit Association Test (IAT). We tested its factorial structure, and the internal and test-retest validity, recruiting a sample of 183 asthmatic people. We also explored the convergent validity and the correlations with objective and subjective clinical assessments.

Results: Data suggested a three-factorial structure of the questionnaire into expectations about future symptoms, change in current health status, and rigidity of these expectations. The questionnaire showed good psychometric properties and strong associations with the other considered outcomes, including implicit expectations. The implicit evaluation, however, lacked test-retest reliability.

Conclusion: The questionnaire is a valid tool to assess illness expectations in people with asthma. The two expectation scales are highly related, and the implicit expectations are moderately associated with the explicit ones. The lack of stability related to IAT results may reflect a lack of stability of the implicit expectations. The implications for the mind/body framework still need to be fully explored.

Keywords: illness expectations, mind/body connection, asthma, placebo, nocebo

\section{Introduction}

A person living with a chronic condition generally develops expectations about the future course of their illness. This expectation is a cognitive schema describing how the illness and its symptoms are anticipated to be in the future, ${ }^{1}$ and they may be explicit - directly accessible to the declarative knowledge, or implicit - outside of the conscious awareness. ${ }^{2}$ These expectations can shape different health behaviors ${ }^{3}$ and are important mediators of the placebo/nocebo response. ${ }^{4}$ Therefore, illness expectations can be particularly relevant for the progression of the disease, with the potential for influencing it either through direct (placebo-related) or indirect (behavior-related) pathways. ${ }^{1}$ The Illness Expectation model also suggests that the rigidity level of these expectations may further influence their impact on symptoms. ${ }^{1}$ The assessment of these schemas, in particular the implicit ones, has been sometimes overlooked by researchers, with few psychological instruments to reliably assess these constructs. Given the peculiarities of each chronic condition, different instruments could be developed for specific clinical conditions. 
Asthma is a chronic and often debilitating inflammatory disease affecting almost 10 billion people in the European Union, with a prevalence estimated at around $8.2 \%{ }^{5}$ It is characterized by recurrent attacks of breathlessness and wheezing, variable expiratory airflow limitation, chronic airway inflammation, and airway hyperresponsiveness. ${ }^{6}$ The unpredictability nature of this disease may lead to a variety of psychological reactions, including fear and anxiety. ${ }^{7}$ For that reason, a certain understanding of the illness can provide a certain sense of control, which in turn promotes an empowering effect. ${ }^{8}$ Despite the importance of illness perception in asthma, it has been only preliminarily explored, ${ }^{9}$ mostly focusing on the effect that emotional representations have on treatment adherence and self-management. ${ }^{10}$ The placebo/nocebo effects have been known for a long time to be relevant for people with asthma. For example, in 1956 a study suggested that just showing an allergen sealed in a transparent container can stimulate a psychogenic attack of asthma. ${ }^{11}$ More recently, exposure to an odor described as "asthmogenic" has been shown to cause an exacerbation of asthma. ${ }^{12}$ More in general, there seems to be a connection between psychological aspects and respiratory problems. In a recent study with a cohort of college students, ${ }^{13}$ we found that the expectation to develop influenza-like symptoms assessed during the fall was greatly associated with the chance of developing them in the winter time. That association remained strong and significant even when accounting for general health or previous flues.

There is no psychometric tool specifically designed to assess illness expectations in asthmatic people. While some general explicit expectations have been included in generic questionnaires, exploration of the implicit association is limited. Therefore, given the relevant role that expectations might play in asthma, a tool for their assessment in the research and clinical setting could be valuable. This study aims to develop and validate a psychometric tool for evaluating the explicit and implicit aspects of illness expectations. The tool is aimed to assess both the explicit and implicit facets of these expectations. Moreover, in line with the Illness Expectation model, ${ }^{1}$ the questionnaire will also provide insight into the level of rigidity of these schemas.

\section{Methods}

\section{Illness Expectation Test for Asthma Development}

As illness expectations are composed of explicit and implicit aspects, the new tool should consider both aspects. Explicit aspects are accessible to declarative knowledge, and could therefore be assessed with standard self-reported methods. The questionnaire items were derived by a set of interviews and focus groups conducted with asthma patients, and it also included items based on the clinical experience of the research team, as well as existing instruments for the assessment of the disease severity (eg, the Asthma Control Test ${ }^{14}$ ), turned into future statements and expectations. The questionnaire consists of 25 items investigating future physical health and symptom status, comparing the current condition to the expected health status at 3 months, and expectations rigidity. A 7-point Likert scale was used for each item (the instrument is reported in the Supplementary - Table S1).

Implicit expectations were assessed with an ad hoc version of the Implicit Association Test (IAT). ${ }^{15}$ The IAT is the most popular and frequently used reaction time instrument to assess automatic associations, and it has been adapted from social cognition to investigating health-related beliefs. ${ }^{16}$ It relies on a response latency indicator obtained in the process of pairing a target object with an attribute. In the computerized version, the pairing is achieved by using the keyboard (eg, left and right keys) to be pressed in response to items from the paired categories. The speed at which this pairing is completed compared to the opposite one is interpreted as a measure of the strength of an implicit attitude. The IAT effect is based on a difference score reflecting both the valence of implicit attitude and the magnitude of the attitude (larger numbers reflecting larger differences between pairings in milliseconds). We selected as target the two concepts of "asthma improvement" and "asthma worsening", and the attribute was set as "me" and "others". Higher scores are supposed to reflect a faster association between "asthma improvement" and "me". The Illness Expectation - Implicit Association Test (IE-IAT) structure followed the classical one developed by Greenwald et al, ${ }^{15}$ and is reported in Table 1.

Once developed, the instrument (both the self-report and the implicit components) were beta-tested in a small sample of asthma patients $(\mathrm{N}=10)$ for clarity, usability, and content appropriateness. The feedback provided by these participants was particularly encouraging, which allowed us to move forward with the data collection phase.

\section{Participants and Procedure}

We recruited 183 asthmatic people either through the outpatient service at Fondazione Don Carlo Gnocchi (FDG) Research Hospital, in Milan, or with the network provided by the FederAsma and Respiriamo Insieme, two Italian associations of people with respiratory diseases. Of these, 
Table I The Illness Expectation - Implicit Association Test (IE-IAT) Structure

\begin{tabular}{|l|c|c|c|c|}
\hline \multicolumn{2}{|c|}{ IE-IAT } & \multicolumn{2}{c|}{ Response Key Assignment } \\
\hline Block & No. of Trials & Task & Left Key & Right Key \\
\hline I & 20 & Target discrimination & Asthma worsening & Asthma improving \\
2 & 20 & Attribute discrimination & Other & Me \\
3 & 20 & First block of first combined task & Asthma worsening, Others & Asthma improving, Me \\
4 & 40 & Second block of first combined task & Asthma worsening, Others & Asthma improving, Me \\
5 & 40 & Reversed target discrimination & Me & Others \\
6 & 20 & First block of second combined task & Asthma worsening, Me & Asthma improving, Others \\
7 & 40 & Second block of second combined task & Asthma worsening, Me & Asthma improving, Others \\
\hline
\end{tabular}

16 were not analyzed because they did not complete the questionnaire. Sixty-two participants recruited at the hospital during a routine medical check, and 105 received the invitation through newsletters and social media by the associations. Of these, 51 returned the retest, after 4 weeks. The sample characteristics are reported in Table 2.

All questionnaires were completed online, through the Qualtrics suite (Qualtrics, Provo, UT). The IE-IAT was developed using a new and specific JavaScript code that allowed to program the task within Qualtrics, provided by the Iatgen tool. ${ }^{17}$ Participants were instructed to access the study link only from a laptop or a desktop computer, as the IAT required a keyboard. Respondents expressed their consent before inserting any data in the survey. After 4 weeks, participants were invited via email to complete the questionnaire again, to verify test-rest validity. $\mathrm{A} € 5$ Amazon gift card was provided to those who completed the questionnaires. The study was approved by the Ethics Commission of the Department of Psychology at Università Cattolica del Sacro Cuore and the Ethics Committee of Fondazione Don Carlo Gnocchi, and was conducted in accordance with the Declaration of Helsinki.

\section{Statistical Analysis}

The factorial structure of the questionnaire was investigated with a principal component analysis, with a Varimax rotation with Kaiser Normalization. The Kaiser-MeyerOlkin (KMO) score and the Bartlett's test of sphericity were used to test the data adequacy for factor analysis. Each factor was tested for internal consistency (Cronbach's alpha) and test-retest validity after 4 weeks (intraclass analysis). The convergent validity was tested against the BIPQ and the ICQ, testing their correlations. The associations among different factors, both implicit and explicit, and the subjective and objective parameters were explored with bivariate correlations. An alpha level of 0.05 was considered significant.

\section{Results \\ Explicit Expectations}

The principal component analysis suggests a threefactorial structure of the questionnaire, explaining $65.31 \%$ of the total variance. The KMO score (0.911) and the Bartlett's test of sphericity $\left(\chi^{2}=3,2072.68 . d f=\right.$ 30. $p<0.001)$ confirmed sampling adequacy. While item saturation was easily attributable in almost all the cases, items \#2 and \#4 could be part of Factors 1 and 2. Guided by a content analysis (they both refer to a comparison between now and the expected condition in 3 months), we assigned them Factor 2. Item saturation is reported in Table 3.

The three factors were respectively labeled: (1) "Absolute expectations", how symptoms and health are expected to be in the future; (2) "Improvement/worsening", how symptoms and health condition will change, compared to the present day; and (3) "Rigidity", how rigid these expectations are. The Cronbach's alphas for each scale were, respectively, $0.916,0.964$, and 0.578 . To compute the scale scores, we considered the average value of the included items. The means and standard deviations were, respectively: 2.621 $(\mathrm{SD}=1.07), 3.140$ ( $\mathrm{SD}=1.41)$, and $5.05 \quad(\mathrm{SD}=1.19)$. The three factors remained stable after 4 weeks. The intraclass correlation values were $0.917(\mathrm{p}<0.001)$ for the scale "Absolute expectations", $0.734(\mathrm{p}<0.001)$ for the scale "Improvement/worsening", and $0.792(\mathrm{p}<0.001)$ for the scale "Rigidity".

The IAT scores (D) were normally distributed and ranged from -.627 to 1.205 , with a mean of 0.516 $(\mathrm{sd}=0.363)$. The test-retest reliability was not verified, as the intraclass correlation was not significant $(0.254$, $\mathrm{p}=0.167)$. 
Table 2 Characteristics of the Study Sample

\begin{tabular}{|c|c|c|c|}
\hline & $\begin{array}{l}\text { Participants } \\
\text { Recruited at } \\
\text { FDG }(n=62)\end{array}$ & $\begin{array}{l}\text { Participants } \\
\text { Recruited } \\
\text { Through the } \\
\text { Associations' } \\
\text { Network } \\
(n=105)\end{array}$ & $\begin{array}{c}\text { All } \\
\text { Participants } \\
(n=167)\end{array}$ \\
\hline \multicolumn{4}{|l|}{ Gender, n (\%) } \\
\hline Male & $21(33.9)$ & $37(36.6)$ & $61(36.5)$ \\
\hline Female & $41(66.1)$ & $64(33.6)$ & $106(63.5)$ \\
\hline \multicolumn{4}{|l|}{ Marital Status, n (\%) } \\
\hline Married & $37(59.7)$ & $52(51.4)$ & $90(53.9)$ \\
\hline Divorced & I (I.6) & $10(9.9)$ & II (6.6) \\
\hline Separated & $4(6.4)$ & $2(1.9)$ & $7(4.2)$ \\
\hline Single & $11(17.7)$ & $23(22.7)$ & $35(2 I)$ \\
\hline Widower & $4(6.4)$ & $2(1.9)$ & $6(3.6)$ \\
\hline Other & $5(8.06)$ & $12(11.8)$ & $18(10.8)$ \\
\hline Age mean (SD) & $54.7(16.7)$ & $45.4(17)$ & $48.9(17.3)$ \\
\hline $\begin{array}{l}\text { Age first symptoms } \\
\text { (SD) }\end{array}$ & $33.3(22.3)$ & $21.7(19.3)$ & $25.6(21)$ \\
\hline \multicolumn{4}{|l|}{ Profession, n(\%) } \\
\hline Employee & $27(43.5)$ & $53(52.5)$ & $82(49.7)$ \\
\hline Freelance & $4(6.4)$ & $10(9.9)$ & $15(9.1)$ \\
\hline Unemployed & $2(3.2)$ & $3(2.9)$ & $5(3)$ \\
\hline Student & $2(3.2)$ & $9(8.9)$ & II (16.5) \\
\hline Retired & $18(17.8)$ & $17(16.8)$ & $35(21.2)$ \\
\hline Other & $7(11.2)$ & $9(8.9)$ & $17(10.3)$ \\
\hline \multicolumn{4}{|l|}{ Spirometry } \\
\hline FVC (SD) & $3.45(1.11)$ & & \\
\hline FVC\% (SD) & $92.4(16.2)$ & & \\
\hline $\mathrm{FEV}_{\mathrm{I}}(\mathrm{SD})$ & $2.68(0.93)$ & & \\
\hline FEVI\% (SD) & $90.2(19.3)$ & & \\
\hline $\begin{array}{l}\text { Tiffeneau-Pinelli } \\
\text { Index \% (SD) }\end{array}$ & $95.8(10.2)$ & & \\
\hline
\end{tabular}

Abbreviations: $\mathrm{FEV}_{\mathrm{l}}$, forced expiratory volume in I second; FVC, forced vital capacity.

The inter-factor correlations, together with the associations with the IAT scores are reported in Table 4. Post hoc analyses indicate that the direction of the correlation between absolute expectations and rigidity was different for those with positive expectations $(\mathrm{R}=0.346, \mathrm{p}=0.012)$ and those with negative expectations $(R=-.174, p=0.07$; see Figure S1).

The correlations that the three scales and the IAT score had with the other considered outcomes are reported in Table 5 .

\section{Discussion}

This study aimed to develop and validate a new instrument for the assessment of illness expectations of people with asthma. While expectations are a relevant psychological construct for the management of chronic illness, no specific instrument for their assessment in the field of respiratory diseases had been developed. The Illness Expectation Test for Asthma measures two aspects of the expectations, namely explicit and implicit ones. Furthermore, in line with the Illness Expectation model, ${ }^{1}$ it provides an evaluation of the rigidity of explicit expectations.

The results from the factor analysis suggest a threefactorial structure, with two different expectation-related components. One factor, labeled "absolute expectations", describes the future scenario (in 3 months) that the person anticipates; in other words, it is a score about how good or bad he/she expects his/her symptoms to be in 3 months. The second factor, labeled "improvement/worsening", represents a comparison between the perception of today and the anticipated condition in 3 months; in other words, it described how much better/worst the subject believes that his/her condition will be in 3 months, compared to today.

The third factor, labeled "rigidity", describes how rigid these expectations are. Aside from the self-reported questionnaire, implicit expectations were assessed with an adhoc implicit association task. This task was based on a classical Implicit Association Test ${ }^{15}$ and adapted to measure the reaction times required to associate asthmarelated positive and negative expectations to the self.

The instrument demonstrated good psychometric properties, in terms of explained variance, internal consistency of the scales, test-retest reliability, and convergent validity. The intra-factor correlations suggest that the two expectation scales are highly related and that the implicit expectations are moderately associated to the explicit ones. The rigidity scale shows a twofolded association with the expectations: the correlation is positive for those with negative expectations (ie, more rigidity, worst expectations) and negative for those with positive expectations (ie, more rigidity, better expectations). In other words, rigidity is associated with both high and low scores, diverging from the central ones. The two expectation scales are positively correlated with the Brief Illness Perception Questionnaire and the helplessness subscale of the Illness Cognition Questionnaire, and negatively correlated with the acceptance subscale; interestingly, the Perceived Benefits subscale was only weekly correlated with the sole improvement/worsening scale. The IAT was negatively (but only moderately) associated with illness perception and helplessness. 
Table 3 Item Saturation and Factorial Structure

\begin{tabular}{|c|c|c|c|c|}
\hline & & \multicolumn{3}{|c|}{ Component } \\
\hline & & $\mathbf{I}$ & 2 & 3 \\
\hline $\mathrm{I}$. & In the next three months, I expect that the symptoms of asthma ... & 0.714 & 0.215 & -.071 \\
\hline 2. & Compared to this period, I expect the symptoms of asthma in the next three months ... & 0.612 & 0.488 & 0.065 \\
\hline 3. & In general, I expect my health to be in the next three months ... & 0.707 & 0.306 & -.018 \\
\hline 4. & Compared to today, I expect my health in the next three months... & 0.682 & 0.422 & 0.025 \\
\hline 5. & I expect that in three months the treatment I am doing will be ... & 0.503 & 0.105 & -.258 \\
\hline 6. & As for the "good days", I expect ... & 0.442 & 0.287 & 0.032 \\
\hline 7. & In the next three months, I expect the presence of a cough ... & 0.721 & 0.195 & -.141 \\
\hline 8. & In the next three months, I expect the presence of phlegm ... & 0.704 & 0.196 & -.25 \\
\hline 9. & In the next three months, I expect a sense of constriction in the chest ... & 0.817 & 0.181 & -.061 \\
\hline 10. & In the next three months, I expect the quality of sleep ... & 0.661 & 0.27 & 0.009 \\
\hline II. & In the next three months, I expect difficulty in breathing ... & 0.799 & 0.321 & -.006 \\
\hline 12. & In the next three months, I expect the presence of whistles and hisses in the breath ... & 0.803 & 0.173 & -.102 \\
\hline 13. & In the next three months, I expect the presence of respiratory attacks ... & $0.8 \mathrm{II}$ & 0.115 & -.092 \\
\hline 14. & In the next three months, I expect episodes of rhinitis ... & 0.477 & 0.306 & -.211 \\
\hline 15. & Compared to today, I expect that cough in the next three months... & 0.378 & 0.847 & -.094 \\
\hline 16. & Compared to today, I expect that in the next three months the phlegm ... & 0.278 & 0.867 & -.118 \\
\hline 17. & Compared to today, I expect that in the next three months the sense of constriction in the chest ... & 0.361 & 0.834 & -.077 \\
\hline 18. & Compared to today, I expect that in the next three months the quality of sleep ... & 0.292 & 0.875 & -.047 \\
\hline 19. & Compared to today, I expect that in the next three months the difficulty in breathing ... & 0.258 & 0.892 & -.005 \\
\hline 20. & Compared to today, I expect that in the next three months the presence of whistles and hisses in my breath ... & 0.227 & 0.913 & -.005 \\
\hline 21. & Compared to today, I expect the presence of respiratory attacks in the next three months... & 0.298 & 0.872 & -.054 \\
\hline 22. & Compared to today, I expect episodes of rhinitis in the next three months ... & 0.138 & 0.886 & -.04 \\
\hline 23. & In general, I change my mind easily & -.012 & -.056 & 0.672 \\
\hline 24. & How sure I am of the answers I gave in the previous answers? & -.298 & -.076 & 0.738 \\
\hline 25. & If I had to bet money on the fact that my predictions will come true, I would bet ... & -.04 & 0.011 & 0.736 \\
\hline
\end{tabular}

Note: Items attributed to each factor are bolded.

Table 4 Inter-Factor and IE-IAT Correlations

\begin{tabular}{|c|c|c|c|c|c|}
\hline & & Absolute Expectations & Improvement/Worsening & Rigidity & IAT (d) Score \\
\hline Absolute expectations & $\begin{array}{l}\text { Pearson Correlation } \\
\text { Sig. (2-tailed) } \\
\mathrm{N}\end{array}$ & $\begin{array}{l}1 \\
162\end{array}$ & $\begin{array}{l}0.639 * * \\
<0.001 \\
162\end{array}$ & $\begin{array}{l}-.235^{* *} \\
0.003 \\
159\end{array}$ & $\begin{array}{l}-.214^{*} \\
0.038 \\
94\end{array}$ \\
\hline Improvement/worsening & $\begin{array}{l}\text { Pearson Correlation } \\
\text { Sig. (2-tailed) } \\
\mathrm{N}\end{array}$ & $\begin{array}{l}0.639 * * \\
<0.001 \\
162\end{array}$ & $\begin{array}{l}1 \\
162\end{array}$ & $\begin{array}{l}-.115 \\
0.149 \\
159\end{array}$ & $\begin{array}{l}-.250^{*} \\
0.015 \\
94\end{array}$ \\
\hline Rigidity & $\begin{array}{l}\text { Pearson Correlation } \\
\text { Sig. (2-tailed) } \\
\mathrm{N}\end{array}$ & $\begin{array}{l}-.235^{* *} \\
0.003 \\
159\end{array}$ & $\begin{array}{l}-.115 \\
0.149 \\
159\end{array}$ & $\begin{array}{l}1 \\
159\end{array}$ & $\begin{array}{l}0.031 \\
0.767 \\
94\end{array}$ \\
\hline IAT (D) score & $\begin{array}{l}\text { Pearson Correlation } \\
\text { Sig. (2-tailed) } \\
\mathrm{N}\end{array}$ & $\begin{array}{l}-.214^{*} \\
0.038 \\
94\end{array}$ & $\begin{array}{l}-.250 * \\
0.015 \\
94\end{array}$ & $\begin{array}{l}0.031 \\
0.767 \\
94\end{array}$ & $\begin{array}{l}1 \\
94\end{array}$ \\
\hline
\end{tabular}

Notes: ${ }^{p} p<0.05 ; *{ }^{*}<0.01$.

Asthma control was related to both absolute and implicit expectations, supporting the idea that expectations for the future highly rely on the perception of the current situation.
That is in line with the negative association between lung function (FVC) and the improvement/worsening subscale: participants who anticipated a negative course of the disease 
Table 5 Convergent Validity of the Scales

\begin{tabular}{|c|c|c|c|c|c|}
\hline & & Absolute Expectations & Improvement/Worsening & Rigidity & IAT (d) Score \\
\hline \multirow[t]{3}{*}{$\mathrm{FVC} \%$} & Pearson Correlation & -.069 & $-.337 * *$ & 0.042 & -.084 \\
\hline & Sig. (2-tailed) & 0.606 & 0.009 & 0.753 & 0.568 \\
\hline & $\mathrm{N}$ & 59 & 59 & 59 & 49 \\
\hline \multirow[t]{3}{*}{ FEV\% } & Pearson Correlation & 0.108 & -.094 & 0.017 & -.093 \\
\hline & Sig. (2-tailed) & 0.41 & 0.476 & 0.9 & 0.52 \\
\hline & $\mathrm{N}$ & 60 & 60 & 60 & 50 \\
\hline \multirow[t]{3}{*}{ ACT } & Pearson Correlation & $-.211 * *$ & -.048 & -.031 & $0.221 *$ \\
\hline & Sig. (2-tailed) & 0.008 & 0.557 & 0.699 & 0.032 \\
\hline & $\mathrm{N}$ & 155 & 155 & 155 & 94 \\
\hline \multirow[t]{3}{*}{ BIPQ } & Pearson Correlation & $0.552 * *$ & $0.310 * *$ & $-.263 * *$ & $-.22 I^{*}$ \\
\hline & Sig. (2-tailed) & $<0.001$ & $<0.001$ & 0.001 & 0.032 \\
\hline & $\mathrm{N}$ & 158 & 158 & 158 & 94 \\
\hline \multirow[t]{3}{*}{ ICQ-H } & Pearson Correlation & $0.510 * *$ & $0.322 * *$ & $-.213 * *$ & $-.315^{* *}$ \\
\hline & Sig. (2-tailed) & $<0.001$ & $<0.001$ & 0.007 & 0.002 \\
\hline & $\mathrm{N}$ & 157 & 157 & 157 & 94 \\
\hline \multirow[t]{3}{*}{ ICQ-A } & Pearson Correlation & $-.45 \mathrm{I} * *$ & $-.202 *$ & $0.466 * *$ & 0.187 \\
\hline & Sig. (2-tailed) & $<0.001$ & 0.011 & $<0.001$ & 0.072 \\
\hline & $N$ & 158 & 158 & 158 & 94 \\
\hline \multirow[t]{3}{*}{ ICQ-PB } & Pearson Correlation & 0.005 & $-.18 I^{*}$ & $0.164 *$ & -.008 \\
\hline & Sig. (2-tailed) & 0.949 & 0.025 & 0.042 & 0.938 \\
\hline & $\mathrm{N}$ & 154 & 154 & 154 & 93 \\
\hline
\end{tabular}

Notes: ${ }^{*} \mathrm{p}<0.05 ;{ }^{*} \mathrm{p}<0.01$.

Abbreviations: ACT, Asthma Control Test; BIPQ, Brief Illness Perception Questionnaire; ICQ-H, Illness Cognition Questionnaire Helplessness; ICQ-A, IIIness Cognition Questionnaire Acceptance; ICQ-PB, Illness Cognition Questionnaire Perceived Benefits.

are already experiencing more severe respiratory issues than the rest of the sample. The association between expectations and respiratory function, however, was not detected for the FEV\% or for other subscales.

While the presence of the IAT provides the opportunity for new insights into the relationship between implicit and explicit expectations, we should note that the test-retest reliability of this instrument was poor. This is in line with other results suggesting that implicit measures express lower stability over time compared to explicit measures. ${ }^{18}$ This lack of stability poses some challenges to research, but it also paves the way to studies that longitudinally explore how the changes in implicit attitudes are associated with health and life events. More in general, the main purpose of this instrument is to be used in longitudinal studies and RCTs, to carefully investigate the relationship between expectations and health. Once this relationship will be fully explored, the assessment of the expectations could be a valuable clinical tool. It could help the clinician to identify those with negative expectancies, who may need objective information or counseling. The scale could also be used to assess what kind of expectations are promoted by the information received by the physician (or their communication style). Moreover, should the longitudinal results confirm the hypothesis of a strong connection between expectations and disease progression, the test could be added to monitor the confounder role of expectations in RCTs, improving the statistical power.

\section{Limitations}

The study includes several limitations. While we aimed to recruit participants with different severity of asthma, the sample was skewed toward those with mild asthma. Therefore, to be generalized, more data with various severity levels should be collected. While the factorial structure was satisfying, two items were attributed to a factor with a lower loading, based on the content analysis. The limitations of the test-retest validity for the IAT were already mentioned, and further investigations are required to better understand the role of implicit expectations. 


\section{Conclusions}

This study focused on people with asthma, using tailored items for respiratory symptoms. The instrument proved to be a reliable and valid way to assess illness expectations in people with asthma, considering both explicit and implicit facets. However, further studies confirming these results are warranted. For example, new research should conduct a confirmatory factor analysis in other datasets, before the measure is deemed suitable for use in clinical populations. The methods used in this study could inform other works testing the illness expectation model in samples with other diagnoses. Furthermore, longitudinal studies are required to understand the potential impact of these psychological aspects on the symptoms, and to develop new strategies to promote $\mathrm{mind} /$ body changes.

\section{Acknowledgments}

This work has been supported by a grant from BIAL Foundation (grant number 220/2018). The funding body had no role in the design of the study and collection, analysis, and interpretation of data and in writing the manuscript.

\section{Disclosure}

Professor Francesco Pagnini reports grants from Bial Foundation during the conduct of the study. The authors reported no other potential conflicts of interest for this work.

\section{References}

1. Pagnini F. The potential role of illness expectations in the progression of medical diseases. BMC Psychol. 2019;7(1):1-5. doi:10.1186/ s40359-019-0346-4

2. Colloca L, Barsky AJ. Placebo and nocebo effects. $N$ Engl J Med. 2020;382(6):554-561. doi:10.1056/NEJMra1907805

3. Hagger MS, Koch S, Chatzisarantis NL, Orbell S. The common sense model of self-regulation: meta-analysis and test of a process model. Psychol Bull. 2017;143(11):1117. doi:10.1037/bul0000118

4. Kern A, Kramm C, Witt CM, Barth J. The influence of personality traits on the placebo/nocebo response: a systematic review. J Psychosom Res. 2020;128:109866. doi:10.1016/j.jpsychores.2019.109866
5. Gibson GJ, Loddenkemper R, Lundbäck B, Sibille Y. Respiratory Health and Disease in Europe: The New European Lung White Book. European Respiratory Society; 2013.

6. Reddel HK, FitzGerald JM, Bateman ED, et al. GINA 2019: a fundamental change in asthma management: treatment of asthma with short-acting bronchodilators alone is no longer recommended for adults and adolescents. Eur Respir Soc. 2019. doi:10.1183/ 13993003.01046-2019

7. Eassey D, Reddel HK, Foster JM, et al. “ ... I've said I wish I was dead, you'd be better off without me": a systematic review of people's experiences of living with severe asthma. J Asthma. 2019;56 (3):311-322. doi:10.1080/02770903.2018.1452034

8. Labor M, Labor S, Jurić I, Fijačko V, Grle SP, Plavec D. Long-term predictors of anxiety and depression in adult patients with asthma. Wien Klin Wochenschr. 2017;129(19-20):665-673. doi:10.1007/ s00508-017-1203-1

9. Kaptein AA, Klok T, Moss-Morris R, Brand PL. Illness perceptions: impact on self-management and control in asthma. Curr Opin Allergy Clin Immunol. 2010;10(3):194-199. doi:10.1097/ACI.0b013e 32833950c1

10. Horne R, Weinman J. Self-regulation and self-management in asthma: exploring the role of illness perceptions and treatment beliefs in explaining non-adherence to preventer medication. Psychol Health. 2002;17(1):17-32. doi:10.1080/08870440290001502

11. Dekker E, Groen J. Reproducible psychogenic attacks of asthma: a laboratory study. J Psychosom Res. 1956;1(1):58-67. doi:10.1016/ 0022-3999(56)90035-6

12. Jaén C, Dalton P. Asthma and odors: the role of risk perception in asthma exacerbation. J Psychosom Res. 2014;77(4):302-308. doi:10.1016/j.jpsychores.2014.07.002

13. Pagnini F, Cavalera C, Volpato E, Banfi P. Illness expectations predict the development of influenza-like symptoms over the winter season. Complement Ther Med. 2020;50:102396. doi:10.1016/j. ctim.2020.102396

14. Juniper E, Guyatt G, Ferrie P, King D. Development and validation of a questionnaire to measure asthma control. Eur Respir J. 1999;14 (4):902-907. doi:10.1034/j.1399-3003.1999.14d29.x

15. Greenwald AG, McGhee DE, Schwartz JL. Measuring individual differences in implicit cognition: the implicit association test. $J$ Pers Soc Psychol. 1998;74(6):1464. doi:10.1037/00223514.74.6.1464

16. Sheeran P, Gollwitzer PM, Bargh JA. Nonconscious processes and health. Health Psychol. 2013;32(5):460. doi:10.1037/a0029203

17. Carpenter TP, Pogacar R, Pullig C, et al. Survey-software implicit association tests: a methodological and empirical analysis. Behav Res Methods. 2019;51(5):2194-2208. doi:10.3758/s13428-019-01293-3

18. Gawronski B, Morrison M, Phills CE, Galdi S. Temporal stability of implicit and explicit measures: a longitudinal analysis. Pers Soc Psychol Bull. 2017;43(3):300-312. doi:10.1177/0146167216684131

\section{Publish your work in this journal}

The Journal of Asthma and Allergy is an international, peer-reviewed open-access journal publishing original research, reports, editorials and commentaries on the following topics: Asthma; Pulmonary physiology; Asthma related clinical health; Clinical immunology and the immunological basis of disease; Pharmacological interventions and new therapies. The manuscript management system is completely online and includes a very quick and fair peer-review system, which is all easy to use. Visit http://www.dovepress.com/testimonials.php to read real quotes from published authors. 